\title{
Evolution of previous sarcoidosis under type 1 interferons given for severe associated disease
}

\author{
C. Charlier*, H. Nunes*, J-C. Trinchet" ${ }^{\#}$, E. Roullet ${ }^{*}$, L. Mouthon ${ }^{+}$, \\ M. Beaugrand ${ }^{\#}$ and D. Valeyre*
}

ABSTRACT: Sarcoidosis is a granulomatous disorder with a well-known $T$ helper (Th) type 1 cell commitment and a key pathogenic role of interferon (IFN)- $\gamma$. However, little is known about the influence of type 1 IFNs, such as IFN- $\alpha$ and IFN- $\beta$, on the course of previous sarcoidosis.

The aim of this study was to determine whether type 1 IFNs can safely be used in patients with sarcoidosis for severe associated disease.

The present study examined a series of four patients with sarcoidosis, treated by IFN- $\alpha$ or IFN- $\beta$ for viral hepatitis (three cases) or multiple sclerosis (one case).

IFN was initiated soon after apparent recovery (three cases) or during a worsening phase of sarcoidosis (one case). Hydroxychloroquine was added in the case with active disease. Patients received interferon for 6-24 months and had close monitoring during and after IFN therapy. Interestingly, no recurrence or exacerbation of sarcoidosis had occurred at 4 yrs of follow up. Two patients were cured from viral hepatitis, whilst treatment for another failed. No neurological progression was observed in the remaining patient.

This series suggests that, despite the $T$ helper type 1 phenotype of sarcoid granulomatous reaction, type 1 interferons do not exacerbate sarcoidosis in remission and this makes their use possible if indicated. However, their effect in persistent forms of the disease needs further evaluation.

KEYWORDS: Granulomatosis, hepatitis B virus, hepatitis C virus, interferon- $\alpha$ and $-\beta$, multiple sclerosis, sarcoidosis

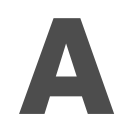
$\mathrm{n}$ abundance of evidence supports the concept that sarcoidosis is a compartmentalised immune disease in which the granulomatous inflammatory lesions involve a highly polarised $\mathrm{T}$ helper (Th) type 1 immune response with upregulated Th1 cytokines, particularly interferon (IFN)- $\gamma$, tumour necrosis factor (TNF)- $\alpha$, interleukin (IL)-2, and IL-18 [1, 2]. Among them, IFN- $\gamma$ is a cornerstone in the pathogenesis [1-4].

IFNs are a family of cytokines divided into type 1 (IFN- $\alpha$ and IFN- $\beta$ ), and type 2 (IFN- $\gamma$ ). IFN- $\alpha$ and IFN- $\beta$ are used as therapeutics in a wide range of diseases. Pegylated IFN- $\alpha$ in combination with ribavirin is the gold standard treatment for viral hepatitis C (HC) [5], leading to $\geqslant 55 \%$ of sustained virological response and consequently decreased risk of cirrhosis and hepatocarcinoma chronic myelogenous leukaemia [8]. IFN- $\beta$ is one of the rare approved disease-modifying therapies in multiple sclerosis (MS) [9].

Since 1987, several cases of sarcoid-like syndromes following type 1 IFN therapy (SLS-IFN) have been reported in patients without previous sarcoidosis [10,11]. Most cases were induced by IFN- $\alpha$, whereas IFN- $\beta$ was responsible for four cases [10-14]. As a result, the risk of exacerbation of previous sarcoidosis became a major concern diseases and one might preclude their use in this context. Thus, the current authors report an interesting series of four patients who received IFN- $\alpha$ or IFN- $\beta$ for comorbidity without relapse or worsening of underlying sarcoidosis (table 1).
[6]. It is also used in viral hepatitis B (HB) [7] and when introducing type 1 IFNs for associated

\section{AFFILIATIONS}

*Pneumology Dept, and

+Internal Medicine Dept, Avicenne University Hospital, Assistance

Publique/Hôpitaux de Paris, Bobigny, \#Hepatology Dept, Jean Verdier University Hospital, Assistance Publique/Hôpitaux de Paris, Bondy, and "Multiple Sclerosis Clinic, Dept of Neurology, Tenon University Hospital, Assistance Publique/Hôpitaux de Paris, Paris, France.

\section{CORRESPONDENCE}

D. Valeyre

Service de Pneumologie

Avicenne Univeristy Hospital

125 route de Stalingrad

93009

Bobigny

France

Fax: 33148955126

E-mail: dominique.valeyre@avc.

ap-hop-paris.fr

Received:

December 222003

Accepted after revision:

October 052004 


\section{TABLE 1 A summarised description of the four cases}

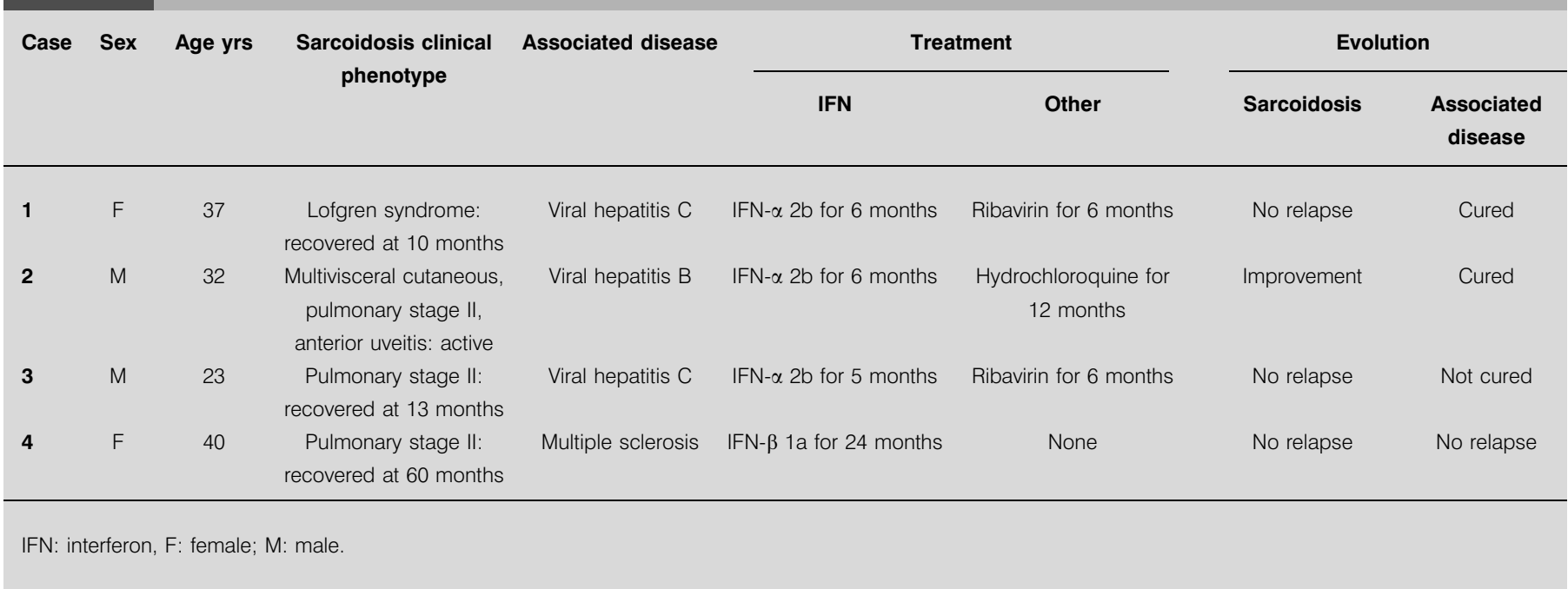

\section{CASE REPORTS \\ Case 1}

A 37-yr-old Caucasian female was diagnosed with sarcoidosis in May 1999, on the association of erythema nodosum, bilateral hilar lymphadenopathies on chest radiograph, increased serum angiotensin converting enzyme (SACE) level and cutaneous granulomatous lesions. Viral HC (genotype 2) with moderate hepatic lesions (Metavir Score A1/F2) was also diagnosed. All signs of sarcoidosis disappeared after 2 months of corticotherapy. In December 1999, a mixed cryoglobulinaemia appeared and histopathological hepatic lesions worsened (Metavir Score A2/F2). IFN- $\alpha$ 2b (3 million units, 3 times week $^{-1}$; Viraferon ${ }^{\circledR}$; Schering-Plough, Kenilworth, NJ, USA) combined with ribavirin $\left(1,200 \mathrm{mg}\right.$ q.d. Rebetol ${ }^{\circledR}$; Schering-Plough) was initiated in May 2000, after follow up failed to reveal any clinical, radiological and SACE abnormality. Complete viral response was achieved 6 months later (i.e. viral replication could not be detected any more) and antiviral therapy was retrieved (as 6 months is the recommended duration of treatment in responder patients with HC, genotype 2). No recurrence of sarcoidosis was observed at scheduled visits until June 2002 (including a monthly clinical examination for the first 3 months, followed by clinical and chest radiographic evaluation every 6 months). HC cure was confirmed in June 2002.

\section{Case 2}

A Black 32-yr-old Caribbean male was diagnosed with multivisceral sarcoidosis and chronic HB infection in June 1991. The patient presented with cutaneous nodules, dyspnoea and radiographic bilateral hilar lymphadenopathies and diffuse pulmonary infiltration. Cutaneous and bronchial biopsies revealed granulomas. Serum HB antigens were present but aminotransferases were normal. Corticosteroids were prescribed until complete clinical and radiographic remission in January 1993. In July 1995, sarcoidosis relapsed with cutaneous nodules, left anterior uveitis and pulmonary infiltration. SACE was four times the upper limit of the normal value $(4 \mathrm{~N})$. Aminotranferases were $10 \mathrm{~N}$. Serum HB viral DNA was
$5 \times 10^{6}$ copies $\cdot \mu \mathrm{L}^{-1}$. A liver biopsy performed in December 1995, revealed chronic viral hepatitis (Metavir Score A2/F1) and granulomas. The chronic course of sarcoidosis made a short-term recovery unlikely; therefore, IFN- $\alpha 2 b$ was initiated ( 3 million units, 3 times week $^{-1}$; Introna $\mathbb{R}$; Schering-Plough) in January 1996. Hydroxychloroquine (400 mg q.d. Plaquenil®; Sanofi-Winthrop, New York, NY, USA) was also given. In June 1996, complete viral response was achieved since HB antigens and viral DNA were not detectable anymore, whilst sarcoidosis improved markedly; cutaneous lesions disappeared, aminotransferases and SACE normalised, uveitis and pulmonary lesions improved. IFN- $\alpha$ was then withdrawn. Hydroxychloroquine was maintained until December 1996. In January 1998, isolate persistent uveitis led to the successful introduction of low doses of prednisone until April 2003 (11 mg q.d.).

\section{Case 3}

A 23-yr-old Caucasian male was diagnosed in 1983 with pulmonary sarcoidosis on the basis of typical hilar lymphadenopathies that spontaneously disappeared. In December 1999, sarcoidosis relapsed with dyspnoea, thoracic lymphadenopathies, nasal granulomas and increased SACE (2N). Viral HC (genotype 1a) with elevated aminotransferases (2N) was verified. Corticosteroids were given until September 2001, with regression of clinical lesions and SACE normalisation. In May 2002, a liver biopsy revealed severe viral hepatitis (Metavir score A2/F2-3). In October 2002, after investigations failed to show any clinical, biological or radiological sign of sarcoidosis, IFN- $\alpha 2 \mathrm{~b}$ (3 million units, 3 times $^{-}$week $^{-1}$; Viraferon $\left.{ }^{\circledR}\right)$ and ribavirin $(1,200 \mathrm{mg}$ q.d.) were initiated. In March 2003, antiviral treatment was stopped due to persistent viral replication. No relapse of sarcoidosis was observed until September 2003 (evaluations scheduled as for case 1).

\section{Case 4}

A 40-yr-old Caucasian female was diagnosed in 1993 with sarcoidosis on hilar bilateral lymphadenopathies and typical bronchial granulomas. All abnormalities regressed with 
corticotherapy until 1996. In 2000, the patient developed vertigo, right pyramidal syndrome and left spino thalamic sensory deficit, consistent with brainstem and spinal cord lesions. Analyses of cerebral fluid revealed elevated immunoglobulin $\mathrm{G}$ index and banding; brain and spinal cord magnetic resonance imaging showed lesions fulfilling established criteria for MS [15]. No relapse of sarcoidosis was observed (normal chest radiograph, thorax computed tomography, gallium scan, pulmonary function, salivary gland biopsy and SACE), for this reason, neurosarcoidosis was ruled out. IFN- $\beta$ 1a (Rebif ${ }^{\circledR}$; Serono, Geneva, Switzerland) was started on July 2001 (44 $\mu \mathrm{g}, 3$ times' week $^{-1}$ ). Until July 2003, neither neurological aggravation nor recurrence of sarcoidosis was observed.

\section{DISCUSSION}

In the present study, the authors report the first series of four consecutive patients with previous sarcoidosis who received type 1 IFNs for associated disease. The current study is relevant to the understanding of sarcoidosis pathogenesis and deserves discussion on the Th1/Th2 paradigm in this condition and on the ability of type 1 IFNs to promote Th1-related diseases. Strikingly, no flare up or relapse of sarcoidosis occurred on close monitoring during type 1 IFN therapy and follow up. Moreover, a beneficial effect of IFN was clear since two patients recovered from viral hepatitis and the patient with MS stabilised.

The presented observations may seem paradoxical. Indeed, although binding distinct cellular receptors, type 1 and 2 IFNs share the same signalling pathways and biological effects [16]. Moreover, type 1 IFNs are classically considered to upregulate IFN- $\gamma$ expression by T-cells [16]. Both these effects might account for the recent reports of SLS-IFN in patients without previous sarcoidosis. In patients with previous sarcoidosis, type 1 IFNs are expected to exacerbate the disease by reinforcing underlying Th1 commitment. However, the real influence of type 1 IFNs on the course of sarcoidosis has remained largely unknown until now, mainly due to the number of published cases being very rare [17-20], and not always well documented.

In the present series, type 1 IFNs were initiated in two very different settings. In three of the cases (1, 3 and 4), sarcoidosis was in remission for $>6$ months from the moment of beginning IFN treatment. In these patients several hypotheses may explain why a previous history of sarcoidosis was not responsible for the later development of SLS-IFN. First, the genotypic pre-disposition to develop sarcoidosis and SLSIFN may be distinct. Secondly, the antigen promoting the granulomatous reaction may have been cleared at the time of type 1 IFN introduction and these drugs may not be sufficient per se to trigger a SLS in these cases. Finally, although type 1 IFNs have long been recognised to promote Th1-related cytokines, several recent studies provide indications that their immunoregulatory effect may be more complex and may depend particularly on the physiological context [16]. For example, during viral infections of mice, type 1 IFNs surprisingly act to inhibit IFN- $\gamma$ expression by T-cells [21]. IFN- $\alpha$ and IFN- $\beta$ prevent the development of experimental auto-immune uveoretinitis, a known Th1-mediated disease [22], and IFN- $\alpha$ has been shown to suppress Th1 responses in patients with human T-cell lymphotrophic virus type 1associated myelopathy [23].

The context was opposite for case 2 who had a chronic active multivisceral form of sarcoidosis, suggesting that the responsible antigen was persistent. The paradoxical improvement of sarcoidosis despite type 1 IFN therapy may be supported by the adjunction of hydrochloroquine, an agent that inhibits antigen presentation. However, hydrochloroquine usually only has a modest effect on severe sarcoidosis [1]. Cytokines profile and particularly the contribution of Th1 and Th2 response has not been specifically addressed in the pathogenesis of long standing forms of sarcoidosis [3]. In such chronic forms, the pathogenic role of IFN- $\gamma$ may be less important and, therefore, the use of type 1 IFNs less harmful.

\section{Conclusion}

Even if the number of patients is small, the present series illustrates that type 1 interferon therapy can be used safely with suitable monitoring in selected patients with a history of sarcoidosis, if it is necessary for severe comorbidity. An observatory listing all the patients with sarcoidosis who required interferon therapy may provide more accurate data about the safety of such an agent, especially in active forms of the disease.

\section{REFERENCES}

1 Baughman RP, Lower EE, Du Bois RM. Sarcoidosis. Lancet 2003; 361: 1111-1118.

2 Bäumer I, Zissel G, Schlaak M, Müller-Quernheim J. Th1/ Th2 cell distribution in pulmonary sarcoidosis. Am J Respir Cell Mol Biol 1997; 16: 171-177.

3 Moller DR. Pulmonary fibrosis of sarcoidosis. New approaches, old ideas. Am J Respir Cell Mol Biol 2003; 29: Suppl. 3, S37-S41.

4 Newman LS, Rose CS, Maier LA. Sarcoidosis. N Engl J Med 1997; 336: 1224-1234.

5 Flamm SL. Chronic hepatitis C virus infection. JAMA 2003; 289: 2413-2417.

6 Degos F, Christidis C, Ganne-Carrie N, et al. Hepatitis C virus related cirrhosis: time to occurrence of hepatocellular carcinoma and death. Gut 2000; 47: 131-136.

7 Ganem D, Prince AE. Hepatitis B virus infection-natural history and clinical consequences. N Engl J Med 2004; 350: 1118-1129.

8 Druker BJ, Sawyers CL, Capdeville R, Ford JM, Baccarani M, Goldman JM. Chronic myelogenous leukemia. Hematology 2001: 87-112.

$9 \mathrm{O}^{\prime}$ Connor P. Key issues in the diagnosis and treatment of multiple sclerosis. Neurology 2002; 59: 1-33.

10 Abdi EA, Nguyen GK, Ludwig RN, Dickout WJ. Pulmonary sarcoidosis following interferon therapy for advanced renal cell carcinoma. Cancer 1987; 59: 896-900.

11 Leclerc S, Myers RP, Moussalli J, Herson S, Poynard T, Benveniste O. Sarcoidosis and interferon therapy: report of five cases and review of the literature. Eur J Intern Med 2003; 14: 237-243.

12 Miwa H, Furuya T, Tanaka S, Mizuno Y. Neurosarcoidosis associated with interferon therapy. Eur Neurol 2001; 45: 288-289. 
13 Bobbio-Pallavicini E, Valsecchi C, Tacconi F, Moroni M, Porta C. Sarcoidosis following $\beta$-interferon therapy for multiple myeloma. Sarcoidosis 1995; 12: 140-142.

14 Mehta Cl, Tyler RJ, Cripps DJ. Granulomatous dermatitis with focal sarcoidal features associated with recombinant interferon $\beta-1 b$ injections. J Am Acad Dermatol 1998; 39: 1024-1028.

15 McDonald WI, Compston A, Edan G, et al. Recommended diagnostic criteria for multiple sclerosis: guidelines from the international panel on the diagnosis of multiple sclerosis. Ann Neurol 2001; 50: 121-127.

16 Biron $C A$. Interferons $\alpha$ and $\beta$ as immune regulator. A new look. Immunity 2001; 14: 661-664.

17 Nakajima M, Kubota Y, Miyashita N, Niki Y, Matsushima T, Manabe T. Recurrence of sarcoidosis following interferon alpha therapy for chronic hepatitis C. Intern Med 1996; 35: 376-379.

18 Li SD, Yong S, Srinivas D, Van Thiel DH. Reactivation of sarcoidosis during interferon therapy. J Gastroenterol 2002; 37: $50-54$.
19 Ohhata I, Ochi T, Kurebayashi S, Matusani H, Kikui M. A case of subcutaneous sarcoid nodules induced by interferon-alpha. Nihon Kyobu Shikkan Gakkai Zasshi 1994; 32: 996-1000.

20 Luers C, Sudhop T, Spengler U, Berthold HK. Improvement of sarcoidosis under therapy with interferon-alpha $2 \mathrm{~b}$ for chronic hepatitis $\mathrm{B}$ virus infection. J Hepatol 1999; 30: 347.

21 Nguyen KB, Cousens LP, Doughty LA, Pien GC, Durbin JE, Biron CA. Interferon alpha/beta-mediated inhibition and promotion of interferon gamma: STAT1 resolves a paradox. Nat Immunol 2000; 1: 70-76.

22 Mizuguchi J, Takeuchi M, Usui M. Type I interferons as immunoregulatory molecules; implications for therapy in experimental autoimmune uveoretinitis. Arch Immunol Ther Exp (Warsz) 2002; 50: 243-254.

23 Feng J, Misu T, Fujihara $\mathrm{K}$, et al. Th1/Th2 balance and HTLV-I proviral load in HAM/TSP patients treated with interferon-alpha. J Neuroimmunol 2004; 151: 189-194. 